\title{
EFICIÊNCIA E EFICÁCIA DE CLUBES DE FUTEBOL - UMA ANÁLISE COMPARATIVA
}

\author{
F.S.M.Carvalho $^{1 *}$; P.O.C.Castro ${ }^{1}$; R.C.S.Guabiroba ${ }^{1}$ \\ 1 Universidade Federal Fluminense, Instituto de Ciências Humanas e Sociais, 27213-145,Volta Redonda - RJ, \\ Brasil \\ *fabiosantosmariano@gmail.com \\ Artigo submetido em 01/03/2016 e aceito em 15/06/2016
}

\section{RESUMO}

O objetivo do artigo é analisar o desempenho de clubes de futebol, comparando clubes brasileiros e clubes europeus. A partir dessa análise, espera-se averiguar três hipóteses: (1) os clubes brasileiros analisados apresentam pior desempenho financeiro em comparação com o desempenho dos clubes europeus; (2) o modelo de gestão escolhido é decisivo para clubes de futebol alcançarem bom desempenho e (3) os clubes de futebol de melhor desempenho financeiro também apresentam mais eficácia com relação à quantidade de vitórias em jogos disputados em 2014. Para alcançar esse objetivo, estruturou um procedimento composto por 4 etapas: (1) definição dos clubes, (2) definição de indicadores e de medidas de desempenho, (3) agregação das medidas para cada clube e (4) ordenação e análise dos clubes. Como resultado dessa análise, verificou-se que são falsas as três hipóteses em discussão. Verificou-se ainda que a maioria dos clubes brasileiros apresentam baixa eficácia e baixo/médio desempenho financeiro. Diferentemente, a maioria dos clubes europeus apresentam alta eficácia e médio/alto desempenho financeiro.

PALAVRAS-CHAVE: clubes, futebol, gestão, desempenho, eficácia.

\section{EFFICIENCY AND EFFECTIVENESS OF FOOTBALL CLUBS - A COMPARATIVE ANALYSIS}

\begin{abstract}
Paper objective is to analyze the performance of football clubs, comparing Brazilian and European club's. From this analysis, it is expected investigate three hypotheses: (1) the analyzed Brazilian clubs have a worse financial performance compared to the performance of European clubs; (2) the chosen management model is crucial for football clubs achieve good performance and (3) football clubs that have high financial performance, also have high efficacy regarding the amount of wins in games played in 2014. To achieve this goal, a procedure was
\end{abstract}

structured in four steps: (1) defining the clubs, (2) development of indicators and performance measures, (3) aggregation of measures for each club and (4) sorting and analysis of clubs. As a result of this analysis, it was found that the three hypotheses under discussion were false. It was also found that most Brazilian clubs have low effectiveness and low/medium financial performance. In contrast, most European clubs have high effectiveness and medium/high financial performance.

KEYWORDS: club, football, management, performance, effectiveness. 


\section{INTRODUÇÃO}

O futebol é um esporte de grande popularidade no Brasil e, de modo global, é um esporte acompanhado por milhares de espectadores. Segundo Silva (2013), esse esporte é conduzido por uma indústria que movimenta grandes quantias, com grandes investimentos, grandes retornos, porém muitas dívidas. Assim, deixando o espetáculo de lado, os clubes de futebol devem ou deveriam buscar aumentar seus retornos e reduzir suas dívidas, independentemente dos modelos de gestão que esses clubes adotaram.

Quando se trata de clubes brasileiros, são muitas as críticas das mídias esportivas, principalmente no que diz respeito às dívidas que acumulam. Assim, de um modo geral, a impressão que se tem é que os clubes brasileiros não são bem administrados, em especial quando comparados com clubes europeus. Sabe-se que os clubes de futebol brasileiros apresentam faturamento geralmente inferior ao dos europeus. No entanto, para analisar o desempenho financeiro desses clubes, deve-se considerar outros indicadores e outras medidas.

Neste contexto, o artigo tem o objetivo de analisar o desempenho de clubes de futebol no mundo, comparando clubes brasileiros e clubes europeus. A partir dessa análise, espera-se averiguar três hipóteses: (1) os clubes brasileiros analisados apresentam pior desempenho financeiro em comparação ao dos clubes europeus; (2) o modelo de gestão escolhido é decisivo para clubes de futebol alcançarem bom desempenho financeiro e (3) os clubes de futebol de melhor desempenho financeiro também apresentam maior eficácia com relação à quantidade de vitórias em jogos disputados em 2014.

Para o alcance do objetivo proposto, foi possível estruturar um método composto por quatro etapas. Essas etapas envolvem a determinação dos clubes de futebol que serão comparados, a seleção de indicadores e de medidas de desempenho, calculadas a partir desses indicadores, que serão utilizadas na análise, a agregação dessas medidas por meio da técnica multicritério conhecida como Análise Relacional Grey (GRA) e, finalmente, a hierarquização dos clubes de futebol e conclusão utilizando ainda uma medida de eficácia.

Neste sentido, o artigo apresenta em sua seção (2) conceitos a cerca de modelos de gestão utilizados pelos clubes de futebol, envolvendo modelos de gestão associativos, privados e mistos. Na seção (3), abordam-se conceitos de indicadores e medidas de desempenho financeiro, incluindo exemplos desses indicadores e dessas medidas. A seção (4) é voltada a apresentar o procedimento para análise de desempenho. Na seção (5), esse procedimento é aplicado considerando clubes de futebol brasileiros e europeus. Finalmente, são apresentadas as considerações, envolvendo as limitações do trabalho e sugestões para novos estudos.

\section{MATERIAIS E MÉTODOS}

Primeiramente foi necessário definir modelos de gestão que os clubes utilizam. Observou-se uma tendência cultural nos modelos no Brasil e na Europa, assim o estudo foi baseado nessa base de dados. Assim, foi possível elaborar indicadores comparativos entre clubes de futebol que representariam os modelos. Após o levantamento das informações, foi possível elaborar um planejamento dos procedimentos.

\subsection{Modelos de gestão utilizados por clubes de futebol}

Segundo Ferreira et al. (2005), Chiavenato (2004) e Crozatti (1998), modelo de gestão é a forma de gerir uma organização onde pessoas possuem um mesmo interesse em desenvolver 
produtos e serviços. Os modelos de gestão devem formar a cultura organizacional, elaborar as hierarquias de poder, criar critérios para avaliação de desempenho e empregar formas de ação na empresa.

Existem três diferentes modelos de gestão utilizados por clubes de futebol: modelo de gestão associativo, modelo de gestão privado e modelo de gestão misto. O modelo de gestão associativo é formado por um grupo de pessoas responsáveis por tomar decisões visando o futuro do clube, onde não há finalidade lucrativa. Apesar desse critério, classificam-se ainda na categoria de associações aqueles que realizam negócios visando o ganho patrimonial da pessoa jurídica, sem proporcionar ganhos aos associados. Assim, segundo Pereira (1999), a procura de vantagens materiais acessórias, indispensáveis à sobrevivência da associação, não lhe retira o caráter não lucrativo do fim social. Neste contexto, verifica-se que este é o modelo de gestão mais presente no Brasil, como também em alguns clubes na Espanha. Segundo Cordeiro (2013), a diferença é que nos grandes clubes espanhóis os departamentos de marketing e de finanças são terceirizados, com a finalidade de profissionalizar a gestão do clube.

Já o modelo de gestão privado é a organizaçao como empresa que tem como objetivo gerar lucro. Destaca-se que poucos clubes de futebol adotam esse modelo no Brasil. Na Inglaterra, grande parte dos clubes utilizam o modelo de gestão privado. De acordo com Leoncini e Silva (2006), esse modelo se popularizou na Inglaterra após ser adotado pelo Manchester United Football Club, que apresentou melhorias de resultados substanciais para o clube.

Há ainda o modelo de gestão misto. Segundo Sampaio et al. (2013), esse modelo possui parte do clube vinculado a empresários e outra parte é de responsabilidade da associação de torcedores que participa do processo decisório do clube. A maior parte da sociedade fica em poder das associações de torcedores e a menor fica em poder de empresários ou de empresas. A ideia desse modelo é manter o poder decisório com os sócios vinculados ao clube. Esse sócios podem votar em reuniões do conselho para eleição da diretoria do clube. Cabe destacar que esse modelo não é utilizado no Brasil, mas muito usado na Alemanha.

\subsection{Medidas e indicadores de desempenho financeiro}

Os indicadores são instrumentos de gestão essenciais nas atividades de monitoramento e avaliação das organizações, pois permitem acompanhar o alcance das metas, identificar avanços, melhorias de qualidade, correção de problemas e necessidades de mudança. Segundo Seges (2009), com os indicadores, é possível estabelecer medidas de desempenho para comparar objetos de estudo. No entanto, antes do cálculo, é necessário verificar se as fontes de informação são confiáveis e precisas.

Segundo Ross et al. (2002), as medidas de desempenho podem ser conceituadas como valores gerados a partir de dois ou mais indicadores. De acordo com Matarazzo (2010), essas medidas possuem a capacidade de potencializar a conclusão sobre um estudo. Além disso, Neely et al. (1995) cita que essas medidas de desempenho são importantes, pois representam uma relação entre valores ou indicadores.

A Tabela 1 apresenta sete medidas de desempenho financeiro, além de seus conceitos e como essas medidas podem ser calculadas (qual a relação de indicadores necessários para a realização do cálculo). 
Tabela 1: Conceito de medidas de desempenho financeiro.

\begin{tabular}{|c|c|c|}
\hline Medida & Conceito & Relação de indicadores \\
\hline Liquidez Corrente & $\begin{array}{l}\text { Refere-se à capacidade de pagamento da empresa no curto } \\
\text { prazo. }\end{array}$ & $\begin{array}{l}\text { Ativo Circulante/Passivo } \\
\text { Circulante }\end{array}$ \\
\hline Giro do ativo total & $\begin{array}{l}\text { Refere-se à capacidade da empresa em usar todos seus } \\
\text { ativos para gerar receita. }\end{array}$ & Receita total/Ativo total \\
\hline Endividamento Geral & Representa o quanto a empresa esta endividada. & $\begin{array}{l}\text { (Passivo Total - Patrimônio } \\
\text { Líquido)/Ativo Total }\end{array}$ \\
\hline $\begin{array}{l}\text { Índice de composição do } \\
\text { endividamento }\end{array}$ & $\begin{array}{l}\text { Representa o percentual da dívida de curto prazo da empresa } \\
\text { com terceiros. }\end{array}$ & $\begin{array}{l}\text { Passivo Circulante/Capitais de } \\
\text { Terceiros }\end{array}$ \\
\hline Retorno do Ativo & $\begin{array}{l}\text { Representa o quanto uma empresa consegue gerar lucro a } \\
\text { partir da utilização de seus ativos. }\end{array}$ & Lucro Líquido/Ativo total \\
\hline $\begin{array}{l}\text { Retorno do Capital } \\
\text { Próprio }\end{array}$ & $\begin{array}{l}\text { Indica o potencial de crescimento da empresa utilizando } \\
\text { capital próprio. }\end{array}$ & $\begin{array}{l}\text { Lucro Líquido/Patrimônio } \\
\text { Líquido }\end{array}$ \\
\hline $\begin{array}{l}\text { Margem de Lucro } \\
\text { líquido }\end{array}$ & $\begin{array}{l}\text { Lucro líquido com relação a cada unidade monetária que } \\
\text { compõe o faturamento da empresa. }\end{array}$ & Lucro Líquido/Receita total \\
\hline
\end{tabular}

Fonte: elaborado pelos autores segundo Gitman (1994) e Ross et al. (2002).

Neste trabalho, os indicadores utilizados são disponibilizados em balanços patrimoniais e em demonstrações de resultados anuais que os clubes de futebol apresentam em suas páginas na Internet. A partir da definição desses indicadores será possível calcular as medidas de desempenho financeiro que permitirão verificar as hipóteses estabelecidas.

\subsection{Procedimento para análise de desempenho}

Para alcançar o objetivo do presente artigo, estruturou-se um procedimento composto por quatro etapas ou passos. A Figura 1 apresenta esses passos: (1) definição dos clubes, (2) definição de indicadores e de medidas de desempenho, (3) agregação das medidas para cada clube e (4) ordenação e análise dos clubes. Assim sendo, ao final da aplicação do procedimento, espera-se conhecer os times de futebol com maior desempenho financeiro.

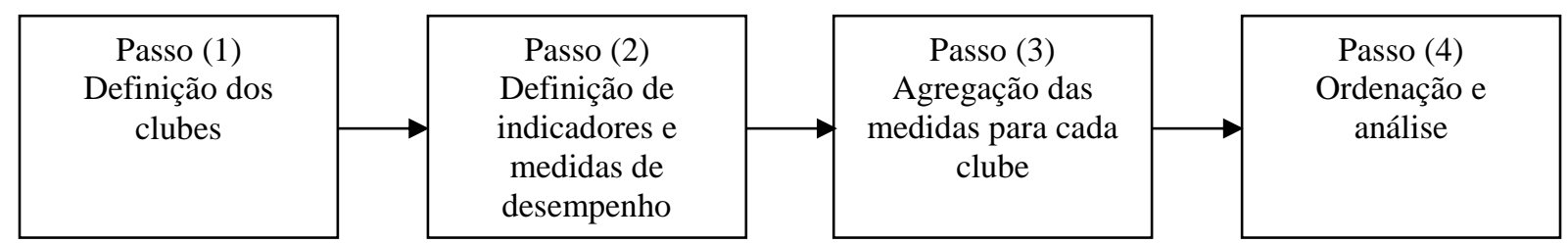

Figura 1: Passos para a análise de desempenho financeiro de clubes de futebol.

No Passo (1), deve-se elencar os clubes de futebol de diferentes modelos de gestão. Esses clubes podem ser apenas nacionais, ser apenas internacionais ou sem essa segregação, caso o objetivo seja comparar clubes independentemente da nacionalidade. Após elencar os clubes, todos podem ser estudados. No entanto, no presente artigo, como o objetivo é comparar clubes de futebol considerando sua nacionalidade ou modelo de gestão, é estabelecido mais um critério de escolha: definir para todos os clubes seu faturamento, de modo a escolher os dois clubes brasileiros de maior faturamento de cada modelo de gestão e escolher ainda os dois clubes internacionais de maior faturamento também de cada modelo de gestão. Sugere-se obter os dados de faturamento a partir de 
balanços patrimoniais e demonstrativos de resultado disponibilizados pelos clubes em suas páginas na Internet.

No Passo (2), são definidas as medidas de desempenho financeiras a serem utilizadas para avaliar os clubes de futebol. De acordo com Gitman (1994) e Dalmácio (2004), as principais medidas de análise financeira são: medidas de liquidez, medidas de endividamento e medidas de rentabilidade. Assim sendo, recomenda-se utilizar como medidas de desempenho para os clubes, as medidas: Liquidez corrente, Giro do ativo total, Endividamento Geral, Índice de composição do endividamento, Retorno do ativo, Retorno do capital e Margem de lucro líquido. Essas medidas são obtidas a partir da relação de indicadores, como faturamento, lucro líquido, ativo total, ativo circulante, ativo não circulante, patrimônio líquido, passivo total, passivo circulante e passivo não circulante. Todos esses indicadores também podem ser obtidos a partir de balanços patrimoniais e demonstrativos de resultado disponibilizados pelos clubes de futebol em suas páginas na Internet. Após obter esses indicadores, as medidas de desempenho devem ser calculadas para cada um dos clubes definidos no Passo (1).

No Passo (3), as medidas definidas no Passo (2) são agregadas. Segundo Bischoff (2008), há diversos métodos de agregação de medidas, como a Análise Relacional Grey, o Método de Análise Hierárquica, a Análise Envoltória de Dados e a Técnica de Avaliação de Desempenho por meio de Similaridade com a Solução Ideal (Técnica TOPSIS). Todas essas técnicas podem ser utilizadas, contudo, pela simplicidade de aplicação, será utilizada para efetuar a agregação das medidas de desempenho, a Análise Relacional Grey. Neste sentido, seja um conjunto de observações \{x0(o), $\mathrm{x} 1(\mathrm{o}), \ldots, \mathrm{xm}(\mathrm{o})\}$, em que se inclui a referência $\mathrm{x} 0(\mathrm{o})$ e as observações originais a serem comparadas x1(o), x2(o), ..., xm(o), representando os clubes de futebol. Cada um dos clubes terá (n) medidas financeiras que podem ser descritas sob a forma de séries $\operatorname{xk}(\mathrm{o})=\{\mathrm{xk}(\mathrm{o})(\mathrm{t}), \ldots, \mathrm{xm}(\mathrm{o})(\mathrm{n})\}$.

Neste contexto, cabe mencionar as etapas da Análise Relacional Grey ou subetapas do Passo (3): (1) normalização de componentes da referida série por meio da Eq. 1, se quanto maior a medida melhor - neste caso enquadram-se as medidas de liquidez corrente, giro do ativo total, retorno do ativo, retorno do capital próprio e margem de lucro liquido - ou por meio da Eq. 2, se quanto menor a medida melhor - neste caso enquadram-se as medidas de endividamento geral e índice de composição de endividamento; (2) definição da observação referencial x0(o) tomada como 1 quando a medida de referência é difícil de ser calculada ou não é facilmente encontrada; (3) definição do coeficiente $\zeta$ que geralmente assume o valor de 0,5; (4) cálculo dos Coeficientes Relacionais Grey por meio da Eq. 3 e (5) determinação dos Graus ( $\Gamma \mathrm{k})$ de Relacionamento Grey para cada clube de futebol, de acordo com a Eq. 4.

$$
\begin{aligned}
& x_{k}^{\prime}(t)=\frac{x_{k}^{(o)}(t)-\min _{\forall k}\left(x_{k}^{(o)}(t)\right)}{\max _{\forall k}\left(x_{k}^{(o)}(t)\right)-\min _{\forall k}\left(x_{k}^{(o)}(t)\right)}, \text { para } k=1, \ldots m, t=1, \ldots n . \\
& x_{k}^{\prime}(t)=\frac{\max _{\forall k}\left(x_{k}^{(o)}(t)\right)-x_{k}^{(o)}(t)}{\max _{\forall k}\left(x_{k}^{(o)}(t)\right)-\min _{\forall k}\left(x_{k}^{(o)}(t)\right)}, \text { para } k=1, \ldots m, t=1, \ldots n .
\end{aligned}
$$

$\mathrm{x}_{\mathrm{k}}{ }_{\mathrm{k}}(\mathrm{t})=$ medida de desempenho dos clubes normalizada;

$\mathrm{x}_{\mathrm{k}}^{(\mathrm{o})}(\mathrm{t})=$ medida de desempenho dos clubes não normalizada;

$\mathrm{k}=$ clube de futebol.

$$
\gamma\left(x_{0}^{\prime}(t), x_{k}^{\prime}(t)\right)=\frac{\min _{\forall k} \min _{\forall t}\left|x_{0}(t)-x_{k}(t)\right|+\zeta \max _{\forall k} \max _{\forall t}\left|x_{0}(t)-x_{k}(t)\right|}{x_{0}(t)-x_{k}(t)+\zeta \max _{\forall k} \max _{\forall t}\left|x_{0}(t)-x_{k}(t)\right|}
$$

$\gamma\left(\mathrm{x}_{0}{ }_{0}(\mathrm{t}), \mathrm{x}_{\mathrm{k}}{ }_{\mathrm{k}}(\mathrm{t})\right)=$ Coeficientes Relacionais Grey;

$\mathrm{x}_{\mathrm{k}}(\mathrm{t})=$ medida normalizada; 
$\mathrm{x}_{0}(\mathrm{t})=$ observação referencial;

$\zeta=$ coeficiente pertencente ao intervalo $[0,1]$.

$$
\Gamma_{\mathrm{k}}=\frac{1}{\mathrm{n}} \sum_{\mathrm{t}=1}^{\mathrm{n}} \gamma_{\mathrm{k}}\left(\mathrm{x}_{0}^{\prime}(\mathrm{t}), \mathrm{x}_{\mathrm{k}}^{\prime}(\mathrm{t})\right)
$$

$\Gamma \mathrm{k}=$ Graus de Relacionamento Grey;

$\gamma_{\mathrm{k}}\left(\mathrm{x}_{0}^{\prime}(\mathrm{t}), \mathrm{x}_{\mathrm{k}}{ }_{\mathrm{k}}(\mathrm{t})\right)=$ Coeficientes Relacionais Grey;

$\mathrm{n}=$ número de medidas de desempenho.

No Passo (4), com apenas uma medida para cada clube de futebol, é possível ordenar esses clubes de acordo com o desempenho financeiro. A partir dessa ordenação, cabe verificar o desempenhos dos clubes brasileiros em relação aos clubes europeus. Além disso, cabe observar se o modelo de gestão escolhido por um clube de futebol é decisivo para alcançar bom desempenho. Por fim, é recomendado aliar à medida de desempenho financeiro agregada uma medida de eficácia para incluir na análise o potencial dos clubes de conquistar resultado. Sugere-se como medida de eficácia o número total de vitórias conquistadas pelos clubes em relação ao número total de jogos em que participaram no ano de 2014. No caso dos clubes europeus, o período é o segundo semestre de 2013 e o primeiro semestre de 2014 (1 ano). A partir da análise conjugada do desempenho finaneiro e da eficácia é possível verificar se os clubes de futebol de maior desempenho financeiro também apresentam maior eficácia.

\section{RESULTADOS E DISCUSSÃO}

Nesta aplicação do procedimento apresentado a partir da Figura 1, serão considerados clubes brasileiros e clubes de outras nacionalidades, como Alemanha, Espanha, França e Inglaterra. Após a definição dos clubes, foi possível obter os indicadores financeiros desses clubes e, a partir desses indicadores, foi possível calcular as medidas de desempenho. Essas medidas foram agregadas por meio da Técnica de Análise Relacional Grey e, por fim, os clubes foram ordenados, considerando apenas a medida agregada de desempenho financeiro.

\section{PASSO 1: DETERMINÇÃO DOS CLUBES}

A Tabela 2 apresenta vinte clubes de futebol, dentre eles clubes brasileiros e clubes europeus que podem se utilizar dos três modelos de gestão existentes: modelo de gestão associativo, modelo de gestão privado e modelo de gestão misto.

Tabela 2: Faturamento e modelo de gestão dos clubes de futebol no Brasil e na Europa.

\begin{tabular}{lllc}
\hline País & Clube de futebol & Modelo de gestão & $\begin{array}{c}\text { Faturamento } \\
\text { (em milhões de reais) }\end{array}$ \\
\hline Brasil & Clubes de Regatas do Flamengo & Associativo & 334,31 \\
Brasil & Sport Club Corinthians Paulista & Associativo & 258,24 \\
Brasil & São Paulo Futebol Clube & Associativo & 253,38 \\
Brasil & Sociedade Esportiva Palmeiras & Associativo & 244,11 \\
Brasil & Red Bull Brasil & Privado & 24,72 \\
Brasil & São Bernardo Futebol Clube & Privado & 7,68 \\
Brasil & Grêmio Osasco Audax Esporte Clube & Privado & 2,68
\end{tabular}




$\begin{array}{lllc}\text { Brasil } & \text { Grêmio Esportivo Osasco } & \text { Privado } & 0,25 \\ \text { Espanha } & \text { Real Madrid Club de Futbol } & \text { Associativo } & 1830,21 \\ \text { Espanha } & \text { Futbol Club Barcelona } & \text { Associativo } & 1613,72 \\ \text { Espanha } & \text { Athletic Bilbao } & \text { Associativo } & 218,67 \\ \text { Espanha } & \text { Club Atlético Osasuna } & \text { Associativo } & 85,98 \\ \text { Inglaterra } & \text { Manchester United Football Club } & \text { Privado } & 1724,94 \\ \text { França } & \text { Paris Saint-Germain } & \text { Privado } & 1579,08 \\ \text { Inglaterra } & \text { Manchester City Football Club } & \text { Privado } & 1379,95 \\ \text { Inglaterra } & \text { Chelsea Football Club } & \text { Privado } & 1291,71 \\ \text { Alemanha } & \text { Fussball Club Bayern München } & \text { Misto } & 1623,37 \\ \text { Alemanha } & \text { Borussia Dortmund } & \text { Misto } & 870,79 \\ \text { Alemanha } & \text { Schalke 04 } & \text { Misto } & 712,29 \\ \text { França } & \text { Olympique Lyonnais } & \text { Misto } & 401,26\end{array}$

Fonte: Deloitte (2015), A. Bilbao (2014), O. Lyonnais (2014), C. A. Osasuna (2014), C. R. Flamengo (2014), S. C. Corinthians P. (2014), São Paulo F. C. (2014), S. E. Palmeiras (2014), R.B. Brasil (2014), São Bernardo F.C. (2014), G.O. Audax E.C. (2014), G.E. Osasco (2014).

Por meio da Tabela 1, é possível notar que não há clubes com modelo de gestão misto no Brasil. Com relação aos clubes que utilizam o modelo de gestão privado no Brasil, poucos disponibilizam seus balanços e demonstrativos financeiros. Neste sentido, observa-se que o modelo de gestão predominante no Brasil é o modelo associativo e, na Europa, não há a predominância de um modelo apenas.

Com relação ao faturamento, este foi obtido a partir do demonstrativo financeiro ou balanço dos clubes de futebol. Esses demonstrativos ou balanços são disponibilizados pelos clubes em suas páginas na Internet. Após coletar as informações dos demonstrativos ou balanços, estas foram convertidas para moeda brasileira (câmbio do dia 20/05/2015, em que $\mathrm{R} \$ 1,00=€ 3,33$ e $\mathrm{R} \$ 1,00=$ $£ 3,98$ ). Por meio da Tabela 2 , é possível observar o faturamento dos clubes. O faturamento dos clubes europeus, em sua maioria, é superior (em média seis vezes superiores) ao faturamento dos clubes brasileiros. Neste contexto, e conforme estabelece o procedimento, será realizada a análise de desempenho financeiro dos dois clubes brasileiros e europeus de maior faturamento de cada modelo de gestão. De acordo com a Tabela 2, esses clubes são: Clubes de Regatas do Flamengo, Sport Club Corinthians Paulista, Red Bull Brasil, São Bernardo Futebol Clube, Real Madrid Club de Futbol, Futbol Club Barcelona, Manchester United Football Club, Paris Saint-Germain, Fussball Club Bayern München e Borussia Dortmund. Em virtude da dificuldade de se obter todas as informações financeiras do clube Paris Saint-Germain, este será substituído na análise pelo próximo clube da Tabela 2, o clube Manchester City Football Club.

\section{PASSO 2: DEFINIÇÃO DE INDICADORES E MEDIDAS DE DESEMPENHO}

Após obter os demonstrativos e balanços financeiros disponibilizados pelos clubes de futebol em suas páginas na Internet, foi possível definir os indicadores financeiros a serem utilizados para calcular as medidas de desempenho financeiro. A Tabela 3 apresenta esses indicadores relativos ao ano de 2014, todos convertidos para moeda brasileira. 
Tabela 3: Valores de indicadores financeiros de clubes de futebol em 2014 (em milhões de reais).

\begin{tabular}{|c|c|c|c|c|c|c|c|c|c|}
\hline Clubes de Futebol & 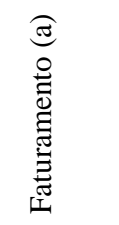 & 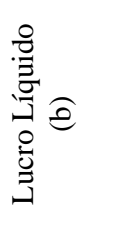 & 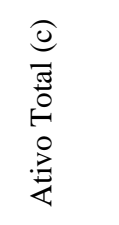 & 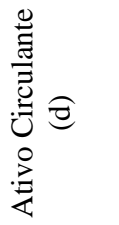 & 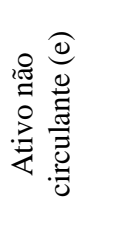 & 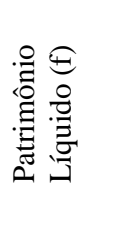 & $\begin{array}{l}\underset{\pi}{0} \\
0 \\
0 \\
0 \\
0 \\
0 \\
0 \\
0 \\
0\end{array}$ & 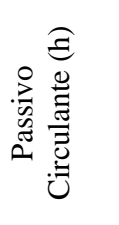 & 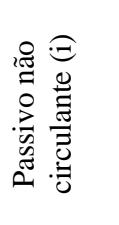 \\
\hline C. R. Flamengo & 334,31 & 64,31 & 429,91 & 104,25 & 325,75 & $-379,08$ & 808,98 & 274,69 & 534,35 \\
\hline Red Bull Brasil & 24,71 & $-0,28$ & 7,29 & 1,55 & 5,78 & $-0,63$ & 7,92 & 7,92 & 0 \\
\hline F. C. Bayern München & 1623,37 & 54,61 & 1766,56 & 622,37 & 1144,18 & 1348,65 & 417,91 & 17,31 & 400,59 \\
\hline Manchester United F. C. & 1724,94 & 94,83 & 4837,73 & 761,98 & 4075,74 & 1984,36 & 2853,44 & 1200,66 & 1652,77 \\
\hline F. C. Barcelona & 1613,72 & 136,53 & 1644,24 & 449,00 & 1195,22 & 178,28 & 1465,95 & 1261,29 & 204,66 \\
\hline S. C. Corinthians & 258,24 & $-97,02$ & 1453,12 & 177,15 & 1275,97 & 306,45 & 1146,67 & 304,64 & 842,03 \\
\hline Real Madrid C. F. & 1830,21 & 160,56 & 3238,18 & 885,94 & 2352,24 & 1233,68 & 2004,50 & 1200,31 & 804,19 \\
\hline São Bernardo F. C. & 7,68 & 0,15 & 1,34 & 0,026 & 1,32 & 0,68 & 0,67 & 0,67 & 0 \\
\hline Borussia Dortmund & 870,79 & 39,86 & 973,32 & 142,52 & 830,80 & 483,68 & 489,64 & 236,46 & 253,18 \\
\hline Manchester City F. C. & 1379,95 & 212,34 & 3083,2 & 880,35 & 2202,85 & 2277,50 & 743,70 & 465,50 & 278,20 \\
\hline
\end{tabular}

Fonte: C. R. Flamengo (2014), R. B. Brasil (2014), F. C. Bayern München (2014), Manchester U. F. C. (2014), F. C. Barcelona (2014), S. C. Corinthians P. (2014), Real Madrid C. F. (2014), São Bernardo F. C. (2014), Borussia D.

(2014) e Manchester City F. C. (2014).

Já a Tabela 4 apresenta as medidas de desempenho financeiro calculadas. Com relação à medida de liquidez corrente, destaca-se o clube Fussball Club Bayern München com a mais alta medida, indicando a grande capacidade de pagamento do clube em curto prazo. No caso da medida de Giro do ativo total, destaca-se o São Bernardo Futebol Clube com maior medida. Isto indica a alta capacidade do clube em usar todos seus ativos para gerar receita.

Tabela 4: Medidas de desempenho financeiro dos clubes de futebol em 2014.

\begin{tabular}{|c|c|c|c|c|c|c|c|c|}
\hline Clubes de Futebol & 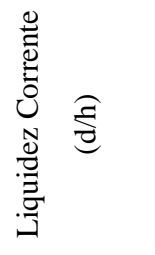 & 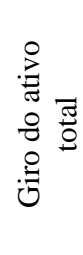 & $\frac{0}{3}$ & 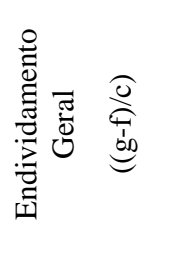 & 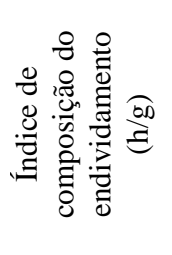 & 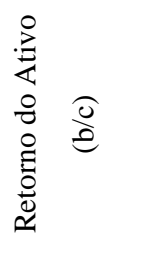 & 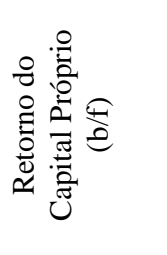 & 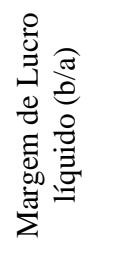 \\
\hline C. R. Flamengo & 0,3795 & & 0,7776 & 2,7635 & 0,3396 & 0,1496 & $-0,1696$ & 0,1924 \\
\hline Red Bull Brasil & 0,1957 & & 3,3896 & 1,1728 & 1,0000 & $-0,0384$ & 0,4444 & $-0,0113$ \\
\hline F. C. Bayern München & 35,9544 & & 0,9189 & $-0,5269$ & 0,0414 & 0,0309 & 0,0405 & 0,0336 \\
\hline Manchester United F. C. & 0,6346 & & 0,3566 & 0,1796 & 0,4208 & 0,0196 & 0,0478 & 0,0550 \\
\hline F. C. Barcelona & 0,3560 & & 0,9814 & 0,7831 & 0,8604 & 0,0830 & 0,7658 & 0,0846 \\
\hline S. C. Corinthians & 0,5815 & & 0,1777 & 0,5782 & 0,2657 & $-0,0668$ & $-0,3166$ & $-0,3757$ \\
\hline Real Madrid C. F. & 0,7381 & & 0,5652 & 0,2380 & 0,5988 & 0,0496 & 0,1301 & 0,0877 \\
\hline São Bernardo F. C. & 0,0388 & & 5,7313 & $-0,0075$ & 1,0000 & 0,1119 & 0,2206 & 0,0195 \\
\hline Borussia Dortmund & 0,6027 & & 0,8947 & 0,0061 & 0,4829 & 0,0410 & 0,0824 & 0,0458 \\
\hline Manchester City F. C. & 1,8912 & & 0,4476 & $-0,4975$ & 0,6259 & 0,0689 & 0,0932 & 0,1539 \\
\hline
\end{tabular}

Verifica-se ainda o Endividamento Geral e o Índice de composição do endividamento (quanto menor melhor), com destaque para o clube Fussball Club Bayern München, o que indica 
que o clube está relativamente menos endividado e, além disso, com baixa dívida de curto prazo com terceiros em relação aos outros clubes de futebol em análise.

Com relação à medida de retorno do ativo, destaca-se o Clube de Regatas Flamengo com maior medida, o que indica maior potencial para gerar lucro a partir da utilização dos ativos do clube. Já a medida de Retorno do Capital Próprio é maior para o Clube Barcelona. Isto indica que este é o clube com maior potencial de crescimento utilizando capital próprio. Por fim, ao observar a medida relativa à margem de lucro líquido, conclui-se que a maior medida é a do Clube de Regatas Flamengo. Isto significa que este clube apresenta o maior lucro líquido com relação a cada unidade monetária de seu faturamento.

\section{PASSO 3: AGREGAÇÃO DAS MEDIDAS PARA CADA CLUBE DE FUTEBOL}

A partir da técnica multicritério Análise Relacional Grey, é possível agregar as medidas de desempenho financeiro, apresentadas na etapa anterior, para cada clube de futebol. A primeira etapa dessa técnica é normalizar cada medida de cada clube de futebol a partir das Equações (1) e (2), conforme apresenta a Tabela 5.

Cabe salientar que a Equação 2 foi utilizada para normalizar as medidas de Endividamento Geral e o Índice de composição do endividamento, pois para estas quanto menor a medida melhor. Já as outras medidas foram normalizadas pela Equação (1) - quanto maior a medida melhor.

Tabela 5: Medidas de desempenho financeiro normalizadas para cada clube de futebol.

\begin{tabular}{|c|c|c|c|c|c|c|c|}
\hline Clubes de Futebol & 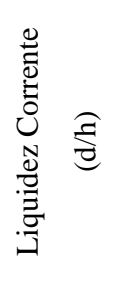 & 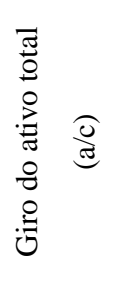 & 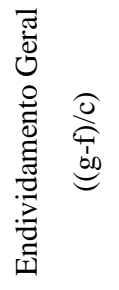 & 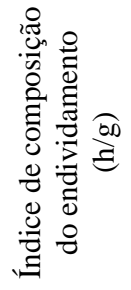 & 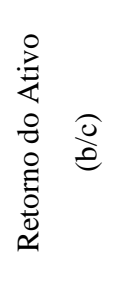 & 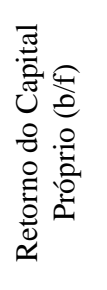 & 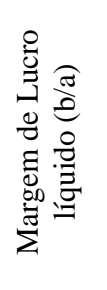 \\
\hline C. R. Flamengo & 0,0095 & 0,1080 & 0,0000 & 0,6890 & 1,0000 & 0,1358 & 1,0000 \\
\hline Red Bull Brasil & 0,0044 & 0,5783 & 0,4834 & 0,0000 & 0,1311 & 0,7031 & 0,6414 \\
\hline F. C. Bayern München & 1,0000 & 0,1335 & 1,0000 & 1,0000 & 0,4515 & 0,3299 & 0,7206 \\
\hline Manchester United F. C. & 0,0166 & 0,0322 & 0,7853 & 0,6043 & 0,3992 & 0,3366 & 0,7581 \\
\hline F. C. Barcelona & 0,0088 & 0,1447 & 0,6019 & 0,1456 & 0,6924 & 1,0000 & 0,8103 \\
\hline S. C. Corinthians & 0,0151 & 0,0000 & 0,6641 & 0,7661 & 0,0000 & 0,0000 & 0,0000 \\
\hline Real Madrid C. F. & 0,0195 & 0,0698 & 0,7675 & 0,4185 & 0,5378 & 0,4127 & 0,8158 \\
\hline São Bernardo F. C. & 0,0000 & 1,0000 & 0,8421 & 0,0000 & 0,8260 & 0,4963 & 0,6957 \\
\hline Borussia Dortmund & 0,0157 & 0,1291 & 0,8380 & 0,5394 & 0,4979 & 0,3686 & 0,7419 \\
\hline Manchester City F. C. & 0,0516 & 0,0486 & 0,9911 & 0,3902 & 0,6269 & 0,3786 & 0,9322 \\
\hline
\end{tabular}

Em seguida, na segunda etapa da técnica, foi definida a observação referencial x0(o) igual a 1 (um), observação normalmente utilizada. Considerou-se ainda o coeficiente $\zeta$ igual a 0,5 , na terceira etapa da técnica. Na sequência, os Coeficientes Grey foram calculados a partir da Equação (3). A Tabela 6 apresenta esses coeficientes para cada um dos clubes de futebol. 
Tabela 6: Coeficientes relacionais Grey definidos para cada clube de futebol.

\begin{tabular}{|c|c|c|c|c|c|c|c|}
\hline Clubes de Futebol & 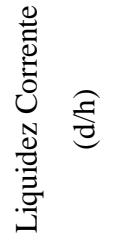 & 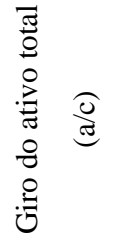 & 总 & 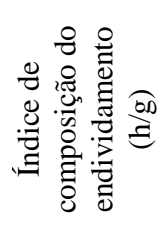 & 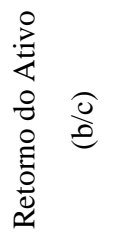 & 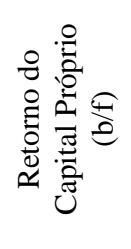 & 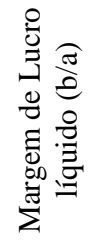 \\
\hline C. R. Flamengo & 0,3355 & 0,3592 & 0,3333 & 0,6165 & 1,000 & 0,3665 & 1,0000 \\
\hline Red Bull Brasil & 0,3343 & 0,5425 & 0,4919 & 0,3333 & 0,3652 & 0,6274 & 0,5824 \\
\hline F. C. Bayern München & 1,0000 & 0,3659 & 1,0000 & 1,0000 & 0,4769 & 0,4273 & 0,6415 \\
\hline Manchester United F. C. & 0,3371 & 0,3406 & 0,6996 & 0,5582 & 0,4542 & 0,4298 & 0,6740 \\
\hline F. C. Barcelona & 0,3353 & 0,3689 & 0,5567 & 0,3692 & 0,6191 & 1,0000 & 0,7250 \\
\hline S. C. Corinthians & 0,3367 & 0,3333 & 0,5982 & 0,6813 & 0,3333 & 0,3333 & 0,3333 \\
\hline Real Madrid C. F. & 0,3377 & 0,3496 & 0,6826 & 0,4623 & 0,5196 & 0,4599 & 0,7308 \\
\hline São Bernardo F. C. & 0,3333 & 1,0000 & 0,7600 & 0,3333 & 0,7418 & 0,4981 & 0,6217 \\
\hline Borussia Dortmund & 0,3369 & 0,3647 & 0,7553 & 0,5205 & 0,4989 & 0,4419 & 0,6596 \\
\hline Manchester City F. C. & 0,3452 & 0,3445 & 0,9824 & 0,4505 & 0,5727 & 0,4459 & 0,8807 \\
\hline
\end{tabular}

Finalmente, a partir da Equação (4), calcula-se os Graus de Relacionamento Grey para cada clube de futebol conforme apresenta a Tabela 7. Esses Graus são as medidas de desempenho financeiro agregadas. Com apenas uma medida para cada clube, agora é possível efetuar a ordenação por desempenho.

\section{PASSO 4: ORDENAÇÃO E ANÁLISE DE DESEMPENHO DOS CLUBES}

A Tabela 7 apresenta ainda a ordenação dos clubes de futebol. Com relação à hipótese de que os clubes brasileiros analisados teriam pior desempenho financeiro em comparação com o desempenho financeiro dos clubes europeus, é possível concluir, de acordo com o período analisado, que essa hipótese é falsa. São Bernardo F.C. e o Clube de Regatas Flamengo, clubes brasileiros com bom desempenho, ocupam respectivamente, a segunda e a quarta posição.

Tabela 7: Medidas agregadas de desempenho financeiro para cada clube de futebol.

\begin{tabular}{|c|c|c|c|c|c|}
\hline Ordenação & Clubes de Futebol & País & Modelo de gestão & $\begin{array}{l}\text { Graus de } \\
\text { relacionamento Grey }\end{array}$ & Eficácia* \\
\hline $1^{\circ}$ & Fussball Club Bayern München & Alemanha & Misto & 0,7017 & $80 \%$ \\
\hline $2^{\circ}$ & São Bernardo Futebol Clube & Brasil & Privado & 0,6126 & $35 \%$ \\
\hline $3^{\circ}$ & Manchester City & Inglaterra & Privado & 0,5746 & $69 \%$ \\
\hline $4^{\circ}$ & Clube de Regatas Flamengo & Brasil & Associativo & 0,5730 & $49 \%$ \\
\hline $5^{\circ}$ & Futbol Club Barcelona & Espanha & Associativo & 0,5677 & $68 \%$ \\
\hline $6^{\circ}$ & Borussia Dortmund & Alemanha & Misto & 0,5111 & $70 \%$ \\
\hline $7^{\circ}$ & Real Madrid Club de Futbol & Espanha & Associativo & 0,5061 & $77 \%$ \\
\hline $8^{\circ}$ & Manchester United Football Club & Inglaterra & Privado & 0,4991 & $50 \%$ \\
\hline $9^{\circ}$ & Red Bull Brasil & Brasil & Privado & 0,4681 & $51 \%$ \\
\hline $10^{\circ}$ & S.C. Corinthians Paulista & Brasil & Associativo & 0,4214 & $52 \%$ \\
\hline
\end{tabular}

* número total de vitórias / número total de jogos em 2014.

Fonte: Adaptado de Ogol (2015). 
Deve-se verificar ainda a hipótese do modelo de gestão escolhido ser decisivo para os clubes de futebol alcançarem bom desempenho financeiro. Verifica-se que essa hipótese também é falsa, uma vez que há clubes com mesmo modelo de gestão que ocupam diferentes posições no ranking. Isto indica que, independente do modelo de gestão escolhido pelo clube, é possível obter um bom desempenho financeiro. Vale citar o São Bernardo Futebol Clube e o Red Bull Brasil. Ambos os clubes atuam com o modelo de gestão privado, contudo o primeiro clube apresenta um desempenho financeiro superior em relação ao segundo clube.

É interessante observar ainda que o tamanho do faturamento não determina o desempenho dos clubes. Os clubes Manchester United Football Club e Real Madrid Club de Futbol possuem os maiores faturamentos do futebol no mundo. No entanto, esses clubes apresentam o terceiro e o quarto pior desempenho, respectivamente, conforme Tabela 7.

Por fim, para completar a análise, é necessário definir uma medida de eficácia, para, em conjunto com a medida de desempenho financeiro, verificar a hipótese de que os clubes de futebol de maior desempenho financeiro também apresentam maior eficácia. Ainda por meio da Tabela 7 , apresenta-se a medida de eficácia que se trata da relação entre o número de vitórias conquistadas pelos clubes de futebol e o número total de jogos em que esses clubes participaram. A partir desses dados de eficácia e das medidas de desempenho financeiro agregadas (Graus de Relacionamento Grey) foi possível elaborar um gráfico composto por quatro quadrantes, conforme apresenta a Figura 2. Constata-se que a última hipótese apresentada é falsa, isto é, nem todos os clubes de futebol de maior desempenho financeiro também apresentam maior eficácia.

Além disto, a Figura 2 permite comparar o desempenho dos clubes brasileiros com relação ao desempenho dos clubes europeus. Constata-se que os clubes brasileiros analisados encontram-se no Quadrante 3 e no Quadrante 4. Esses clubes apresentam baixa eficácia e baixo/médio desempenho financeiro (com exceção ao São Bernardo F. C. que apresenta alto desempenho financeiro). Já os clubes europeus analisados, em sua maioria, com exceção do Manchester United F. C., encontram-se no Quadrante 1 e no Quadrante 2. Nesses quadrantes, esses clubes apresentam alta eficácia e médio/alto desempenho financeiro.

Ao analisar a Figura 2, destaca-se ainda o F. C. Bayern München $\left(\mathrm{N}^{\circ} .1\right.$ do ranking, conforme Tabela 7). Esse clube alemão apresenta alta eficácia e alto desempenho financeiro. Em contrapartida, destaca-se o S. C. Corinthians Paulista em outra vertente: eficácia abaixo da média da eficácia dos clubes de futebol analisados e também baixo desempenho financeiro.

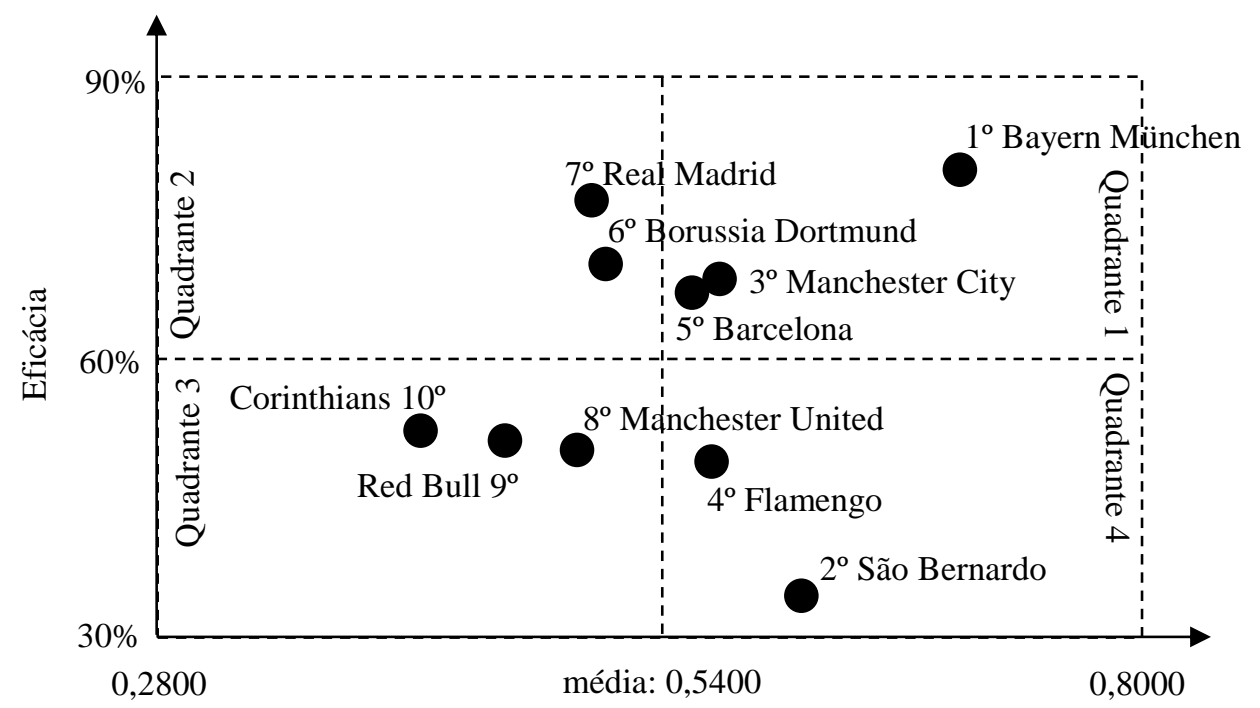

Figura 2: Matriz de desempenho financeiro e eficácia de clubes de futebol no mundo. 
No quadro acima (Figura 2) observamos que o Quadrante 1 encontram-se clubes com alto desempenho financeiro e alta eficácia. No Quadrante 2, os que apresentaram baixo desempenho financeiro e alta eficácia. Quadrante 3, classificam-se clubes com baixo desempenho financeiro e baixa eficácia. E por fim, no Quadrante 4, os clubes que possuem alto desempenho financeiro e baixa eficácia. A eficácia foi calculada através do número total de vitórias em 2014 em relação a quantidade de jogos.

Em uma última análise, ao calcular a média da medida de eficácia e a média da medida de desempenho financeiro dos clubes de futebol de cada país, verifica-se que os clubes alemães apresentam maior medida de eficácia e maior medida de desempenho financeiro, seguidos dos clubes espanhóis e ingleses e, por último, os clubes brasileiros.

\section{CONCLUSÃO}

As críticas distribuídas aos clubes brasileiros em comparação aos clubes europeus são comuns, principalmente provenientes de mídias que abordam o tema esportivo. É conhecido que os clubes brasileiros apresentam faturamento geralmente inferior aos faturamentos dos clubes de futebol europeus. Além disso, não são incomuns críticas aos clubes brasileiros no que diz respeito às dívidas que estes acumulam. Com o objetivo de comparar o desempenho de clubes brasileiros e europeus, o presente artigo buscou averiguar três hipóteses a partir de um procedimento em quatro etapas.

Após aplicar o procedimento, foi possível verificar que as três hipóteses eram falsas. Assim sendo, constatou-se que pontualmente não é possível afirmar que os clubes brasileiros analisados apresentaram pior desempenho financeiro em comparação com o desempenho dos clubes europeus em 2014. Verificou-se que o modelo de gestão escolhido não é decisivo para clubes de futebol alcançarem bom desempenho. Por fim, averiguou-se que os clubes de futebol de maior desempenho financeiro nem sempre apresentaram maior eficácia, medida a partir da relação entre a quantidade de vitórias e o número de jogos disputados em 2014.

No entanto, quando se determina a média da medida de eficácia e a média da medida de desempenho financeiro dos clubes de futebol de cada país, é possível verificar que, de um modo geral, são superiores as medidas de desempenho financeiro e de eficácia dos clubes de futebol de países europeus. Esta conclusão vai de encontro com as críticas recebidas pelos clubes de futebol brasileiros. Assim sendo, de um modo geral, destaca-se que os clubes brasileiros apresentam baixa eficácia e baixo/médio desempenho financeiro e os clubes europeus apresentam alta eficácia e médio/alto desempenho financeiro.

Cabe ainda salientar que os indicadores financeiros utilizados para calcular as medidas de desempenho foram obtidos por meio dos demonstrativos ou balanços disponibilizados pelos clubes de futebol em suas páginas na Internet. Neste sentido, a limitação do presente estudo foi ter que estabelecer a premissa de que esses dados realmente são certificados, de forma que não tenham sido manipulados pelos clubes para alcançar benefícios fiscais ou tributários.

Finalmente, recomenda-se para novos estudos incluir em uma análise de desempenho mais clubes de futebol, não apenas clubes brasileiros e clubes europeus, mas também outros clubes latinos, clubes americanos e clubes asiáticos. Com relação à medida de eficácia, pode-se considerar o número de títulos conquistados em relação ao total de campeonatos disputados. Com relação ao método de agregação das medidas, sugere-se utilizar outro método ou mais de um método em comparação com o método de Análise Relacional Grey. Como última sugestão, é recomendado 
utilizar outras ou mais medidas de desempenho financeiro em complemento às medidas de desempenho já utilizadas no presente trabalho.

\section{REFERENCIAS}

ATHLETIC C.B. Balanços e demonstrativos financeiros. Athletic Club Bilbao, 2014. Disponível em: <http://www.athletic-club.eus/cas/datos-del-club.html>

BISCHOFF, E. Estudo da utilização de algoritmos genéticos para seleção de redes de acesso. Dissertação (mestrado). Universidade de Brasília, Brasília, 2008.

BORUSSIA D. Balanços e demonstrativos financeiros. Borussia Dortmund, 2014. Disponível em: <http://aktie.bvb.de/eng/Publications/Annual-Reports/Annual-Report-2013-2014-KGaA-Group〉.

C.A. OSASUNA. Balanços e demonstrativos financeiros. Clube Atletico Osasuna, 2014. Disponível em: <http://www.osasuna.es/uploads/archivos/presupuestos-2014-2015.pdf>

CHIAVENATO, I. Introdução à teoria geral da administração: uma visão abrangente da moderna administração das organizações. $7^{a}$ Edição. Rio de Janeiro: Elsevier, 2003.

CORDEIRO, A. L. B. Clube de Regatas do Flamengo e FC Barcelona - Aspectos da profissionalização no futebol. Dissertação (Mestrado). Fundação Getúlio Vargas, 2013.

C. R. FLAMENGO. Balanços e demonstrativos financeiros. Clube de Regatas Flamengo, 2014. Disponível em: <http://www.flamengo.com.br/site/download/transparencia\#/collapse15>.

CROZATTI, J. Modelo de gestão e cultura organizacional: conceitos e interações. Caderno de estudos, São Paulo, v. 10, 1998, pp. 01-20.

DALMÁCIO, F. Z. A Evidenciação Contábil: Publicação de Aspectos Sócioambientais e Econômico-Financeiros nas Demonstrações Contábeis. In: Congresso USP Controladoria e Contabilidade, IV, Anais. Congresso USP, São Paulo, 2004.

DELOITTE. Commercial breaks, Football Money League. Sports Business Group, 2015.

F. C. BARCELONA. Balanços e demonstrativos financeiros. Futbol Clube Barcelona, 2014. Disponível em: $\langle$ http://issuu.com/fc_barcelona/docs/report_fc_barcelona_club_english_20>.

F. C. BAYERN MÜNCHEN. Balanços e demonstrativos financeiros. Fussball Club Bayern München, 2014. Disponível em: <https://www.fcbayern.de/media/native/presse-free/Jahresabschluss_Konzern_13-14.pdf.

FERREIRA, V. C. P.; CARDOSO, A. S. R.; CORRÊA, C. J.; FRANÇA, C. F. Modelos de gestão. Série Gestão de Pessoas. Rio de Janeiro: FGV, 2005.

G. E. OSASCO. Balanços e demonstrativos financeiros. Grêmios Esportivo Osasco, 2014. Disponível em: $\langle$ http://www.gremioosasco.com.br/demon_finan/DF_GEO_OSASCO_2014.pdf>.

GITMAN, L. J. Princípios de Administração Financeira. 7ª Edição. São Paulo: Harbra, 1994.

G. O. AUDAX E. C. Balanços e demonstrativos financeiros. Grêmio Osasco Audax Esporte Clube, 2014. Disponível em: <http://www.fpf.org.br/balanco/2014/5728A.pdf>.

LEONCINI, P. L.; SILVA, M. T. A gestão estratégica de clubes de futebol vista através do caso Manchester United. In: Anais XX Encontro Nacional de Engenharia de Produção, Porto Alegre, 2006.

MANCHESTER CITY F. C. Balanços e demonstrativos financeiros. Manchester City Football Club, 2014. Disponível em: 〈http://annualreport.mcfc.co.uk/financial-report/balance-sheets>.

MANCHESTER U. F. C. Balanços e demonstrativos financeiros. Manchester United Football Club, 2014. Disponível em: 〈http://ir.manutd.com/ /media/Files/M/Manutd-IR/Annual\%20Reports/manchester-united-plc-20f-20141027.pdf〉.

MATARAZZO, D. Análise financeira de balanços: abordagem básica e gerencial. $7^{\mathrm{a}}$ Edição. São Paulo: Atlas, 2010.

NEELY, A. D.; GREGORY, M. J.; PLATTS, K. W. Performance measurement system design: a literature review and research agenda. International Journal of Operations \& Production Management, v. 15, no 4, 1995, pp. 80-116.

OGOL. Informações a respeito do número de vitória e jogos disputados em 2014 por clubes de futebol. Disponível em: http://www.ogol.com.br/. 
OLYMPIQUE L. Balanços e demonstrativos financeiros. Olympique Lyonnais, 2014. Disponível em: <http://www.actusnews.com/documents/ACTUS-0-5895-DDR-OL-2013-2014-GB-130115-VDEF.pdf>

PEREIRA, C. M. S. Curso de Direito Civil. V. 1. 19. Ed. Rio de Janeiro: Forense, 1999.

R. B. BRASIL. Balanços e demonstrativos financeiros. Red Bull Brasil, 2014. Disponível em: <www.fpf.org .br/balanco/2014/7014A.pdf>.

REAL MADRID C. F. Balanços e demonstrativos financeiros. Real Madrid Club Futbol, 2014. Disponível em: <http://www.realmadrid.com/cs/Satellite?blobcol=urldata\&blobheader=application\%2Fpdf\&blobkey=id\& blobtable $=$ MungoBlobs\&blobwhere $=1203349468675 \&$ ssbinary $=$ true $>$.

ROSS, S. A.; WESTERFIELD, R. W.; JAFFE, J. F. Administração financeira: Corporate Finance. São Paulo: Atlas, 2002.

SAMPAIO, P. H. C; CASTRO, C. A. A; MESQUITA, L. G. S. Profissionalização da Gestão Estratégica e Crescimento das Receitas Financeiras dos Clubes Brasileiros de Futebol. Projeto Final (Curso de Aperfeiçoamento em Gestão, Marketing e Direito Desportivo). Fundação Getúlio Vargas, 2013.

SÃO BERNARDO F. C. Balanços e demonstrativos financeiros. São Bernardo Futebol Clube, 2014. Disponível em: <http://www.fpf.org.br/balanco/2014/3388A.pdf>.

SÃO PAULO F.C. Balanços e demonstrativos financeiros. São Paulo Futebol Clube, 2014. Disponível em: <http://www.saopaulofc.net/media/109616/SPFC_2015.pdf>.

S. C. CORINTHIANS P. Balanços e demonstrativos financeiros. Sport Clube Corinthians Paulista, 2014. Disponível em: 〈http://www.corinthians.com.br/upload/site/publica\%C3\%A7ao\%2012-2014.pdf>.

S. E. PALMEIRAS Balanços e demonstrativos financeiros. Sociedade Esportiva Palmeiras, 2014. Disponível em: <http://www.palmeiras.com.br/public/upload/documento/uploads/documento_212.pdf>.

SEGES. Melhoria da gestão pública por meio da definição de um guia referencial para medição do desempenho da gestão, e controle para o gerenciamento dos indicadores de eficiência, eficácia e de resultados do programa nacional de gestão pública e desburocratização. Secretaria de Gestão, Ministériodo Planejamento, Governo do Brasil. Brasília-DF, p.12. 2009.

SILVA, E. R. O crescimento do futebol alemão nas últimas cinco temporadas. Dissertação (Gestão e marketing esportivo). Trevisan Escola de negócios, 2013. 